\title{
Escala geográfica: visibilidades e invisibilidades en procesos culturales afrodescendientes (suroccidente de Colombia) ${ }^{*}$
}

DOI: https://doi.org/10.18046/recs.i3o.3330

Geographic Scale: Visibilities and Invisibilities in Afro-descendant
Cultural Processes (Southwest of Colombia)

Yilver Mosquera-Vallejo ${ }^{* *}$

Pontificia Universidad Católica de Chile (Santiago, Chile)

\footnotetext{
* Esta reflexión fue posible gracias al apoyo del Estado chileno, a través de una beca de doctorado nacional, en el año 2016, de la Comisión Nacional de Investigación Científica y Tecnológica (Conicyt) de Chile. Se inscribe, además, en el marco del proyecto en ejecución de tesis doctoral titulado “Geografías de la negridad:prácticas del 'adentro' y 'afuera' en la construcción del territorio en el valle del Patía, 1960-2017 (Colombia)”. Agradezco a María Fernanda Anaya Chamorro por su ayuda en la elaboración de la cartografía temática y sus comentarios a una versión anterior de este manuscrito. Artículo de investigación recibido el 17.12.2018 y aceptado el 05.11.2019.

** Doctor (c) en Geografía por la Pontificia Universidad Católica de Chile (Chile). Geógrafo de la Universidad del Cauca (Colombia). Correo electrónico: yamosquera@uc.cl ORCID: https://orcid.org/oooo-ooo1-9262-9081
} 


\section{Cómo citar/How to cite}

Mosquera-Vallejo, Yilver (2020). Escala geográfica: visibilidades e invisibilidades en procesos culturales afrodescendientes (suroccidente de Colombia). Revista CS, 30, 251-276. https://doi.org/10.18046/recs.i30.3330 


\section{Resumen}

La escala es una construcción sociocultural altamente contingente y fluida, que posibilita pensar, en términos de articulaciones espacializadas, múltiples procesos culturales, sociales y territoriales en diferentes niveles. El propósito de este manuscrito es analizar los procesos de recuperación de tradiciones culturales en el valle del Patía, iniciados en la década de los ochenta, hasta el año 2018, a partir de la conceptualización de escala geográfica como red. Para cumplir esto, se realizó una entrevista semiestructurada a un actor social que ha acompañado desde el comienzo la recuperación de tradiciones, con el fin de comprender, desde su experiencia, cómo los procesos culturales desarrollados en el Patía han sido articulados mediante múltiples redes escalares, conectadas e interactuadas a través de prácticas de visibilidad e invisibilidad geográfica. Finalmente, ello llevó a establecer que la visibilidad geográfica se vincula con prácticas deslocalizadas, mientras que la invisibilidad geográfica se define como práctica "lugarizada".

PALABRAS CLAVE:

escala geográfica, procesos culturales afrodescendientes, valle del Patía

The scale is a highly contingent and fluid socio-cultural construction, which makes possible, in terms of spatialized articulations, to think of multiple cultural, social, and territorial processes at different spatial levels. The purpose of this manuscript is to analyze the recovery processes of cultural traditions in the Patía Valley initiated in the 8os until 2018, based on the conceptualization of geographic scale as a network. To accomplish this, we carried out a semi-structured interview with a social actor that has accompanied the recovery of traditions from the beginning. This, with the aim of understanding, from their experience, how the cultural processes developed in Patía have been articulated through multiple scalar networks, connected and interacted through visibility and invisibility geographical practices. This led us to establish that geographic visibility is linked to delocalized practices, while geographical invisibility is defined as "place-based" practice.

\section{KEYWORDS:}

Geographic Scale, Afro-descendant Cultural Processes, Patía Valley 



\section{Introducción}

Los estudios afrocolombianos, en las últimas tres décadas, han tenido un proceso de consolidación, manifestado principalmente a partir de la eclosión de pesquisas que se iniciaron después del giro al multiculturalismo con la Constitución política de 1991, el Artículo Transitorio 55, y la Ley 70 de 1993 o de comunidades negras (Hurtado-Saa, 2008a; Velandia; Restrepo, 2017). En estas tres décadas, las investigaciones sobre afrocolombianos han oscilado desde distintos lugares de enunciación teórico-político y territoriales. Numerosos artículos, libros, capítulos de libros y coloquios, así como compilaciones de investigaciones acerca de poblaciones negras (Restrepo; Rojas, 2008; Rojas, 2004), dan cuenta de la expansión de estos estudios.

Los enfoques dentro de los cuales se sitúan los análisis incluyen al posestructuralismo (Escobar, 1999), estudios de la subalternidad (Múnera, 1998), teorías poscoloniales (Amador-Jiménez, 2010), opción decolonial (Albán, 2015), giro geográfico (Oslender, 2008), feminismos y teoría queer (Lozano, 2016), giro ontológico (Ruiz-Serna, 2017) y otros campos, como los estudios culturales (Rojas, 2011). Las problemáticas derivadas de estos sustentos teóricos son: giro al multiculturalismo (Wade, 2004); movimientos sociales, espacialidad y resistencia (Oslender, 2002; 2003); acción afirmativa, afrorreparaciones y ciudadanía diferencial (Mosquera-Rosero; León-Díaz, 2009); identificaciones, identidades y subjetividades (Cunin, 2003; Hurtado-Saa, 2008b; Wade, 1999); raza, racialización y racismo (Gil-Hernández, 2015; Zapata, 2015), y pensamiento propio (Arboleda, 2011; Caicedo, 2013; Valderrama-Rentería, 2018), entre otras.

Nos proponemos inscribir este artículo dentro del campo de los estudios afrocolombianos. Sin embargo, esta construcción se hará desde nuestro énfasis disciplinar, es decir, la geografía humana. Principalmente, nos enfocaremos en la teoría de la escala geográfica, teniendo en cuenta que los lenguajes espaciales desplegados en algunas conceptualizaciones de escala son muy poderosos y permitirían complejizar la mirada frente a dinámicas y procesos económicos, sociales, culturales y políticos desarrollados en territorios de la gente negra en Colombia, lo cual debe resaltarse, pues la escala nos ayuda a interrumpir certezas para pensar los espacios afrocolombianos.

El concepto de escala generalmente se asocia con la posibilidad del investigador de hacer zoom, es decir, el detalle con el que puede aproximar o alejar su objeto de análisis. En tanto se toma distancia del objeto, la escala se amplía y generaliza, mientras que entre más se aproxime a dicho objeto el detalle es mayor. La escala al estilo del cursor en Google Earth facilita "jugar" con los pixeles que particularizan o generalizan un área, logrando, a partir de un cambio en la visualización, espacios completamente diferentes. En definitiva, esto permitiría definir unos "niveles de 
análisis" (Valenzuela, 2006) configurados en unidades espaciales modificables, e implicaría entender los territorios en espacios fijos y móviles al mismo tiempo.

De acuerdo con lo anterior, partimos de la idea de escala como red, lo cual supondría imaginar un conjunto de dinámicas y procesos interconectados localizados y distribuidos en diferentes niveles de áreas. Ello nos ha llevado a comprender las escalas no como ubicaciones, sino más bien como procesos relacionales articulados con múltiples redes. Por lo tanto, entre mayor sea el número de conexiones en el marco de dinámicas económicas, políticas, demográficas y culturales, entre otras, mayor será la escala, o viceversa, entre menor sea el número de conexiones entre agentes sociales, la escala será menor.

Desde esta lectura, dado que la red articula relaciones, procesos, interacciones y niveles de análisis, la escala se convierte en una práctica de visibilidades e invisibilidades geográficas. Para el caso de las dinámicas culturales en el valle del Patía, afirmamos que pocos actores sociales, especialmente ancianos en las veredas, tenían los conocimientos tradicionales. Por ende, la práctica cultural (bambuco patiano ${ }^{1}$ ) estaba restringida sociocultural y geográficamente. Esto implicaba una red escalar localizada en las zonas rurales, y su visibilidad geográfica era posible en el plano local, mientras que cuando se cambiaba la escala a nivel regional, esta derivaba en una invisibilidad geográfica, pues circulaba en los caminos veredales, subcuencas y microcuencas por las que transitaban los ancianos poseedores del saber ancestral, y no en la región.

El propósito de este texto es analizar la relación entre los procesos de recuperación de tradiciones culturales en el valle del Patía ${ }^{2}$ (Figura 1) y la idea de escala geográfica como red, para lo cual realizamos una entrevista semiestructurada al profesor Adolfo Albán Achinte, que presentaremos ipsis literis en algunas partes. Con la entrevista, buscamos elaborar el texto que dará contexto a la siguiente hipótesis: los procesos culturales desarrollados en el valle del Patía a partir de finales de los años ochenta hasta el 2018 han sido articulados mediante múltiples redes escalares conectadas e interactuadas en diferentes prácticas de visibilidad e invisibilidad geográfica. Trazamos este camino porque el aporte de Albán a la recuperación de dinámicas culturales ha sido el resultado de un trabajo continuo desde finales de la década de los ochenta. Usamos la categoría de escala como una red, tanto en el sentido epistemológico como en el ontológico (Gutiérrez-Puebla, 2001; Herod, 2008), para establecer su relación

1. El bambuco patiano es un género musical producto de procesos de hibridación de raíces africanas y europeas. Este se toca, baila y dramatiza con tiple, violín y guitarras, entre otros instrumentos musicales. El bambuco de los patianos deviene en familiaridad, territorialidad y amistad (Muñoz, 2004). 
con las dinámicas culturales en el valle del Patía. Como epistemología, supone una modalidad de conocer o representar al Patía, es decir, leer aquellas planicies como construcciones socioculturales; como ontología, tiene que ver con definir ese valle interandino en tanto estructura espacial existente.

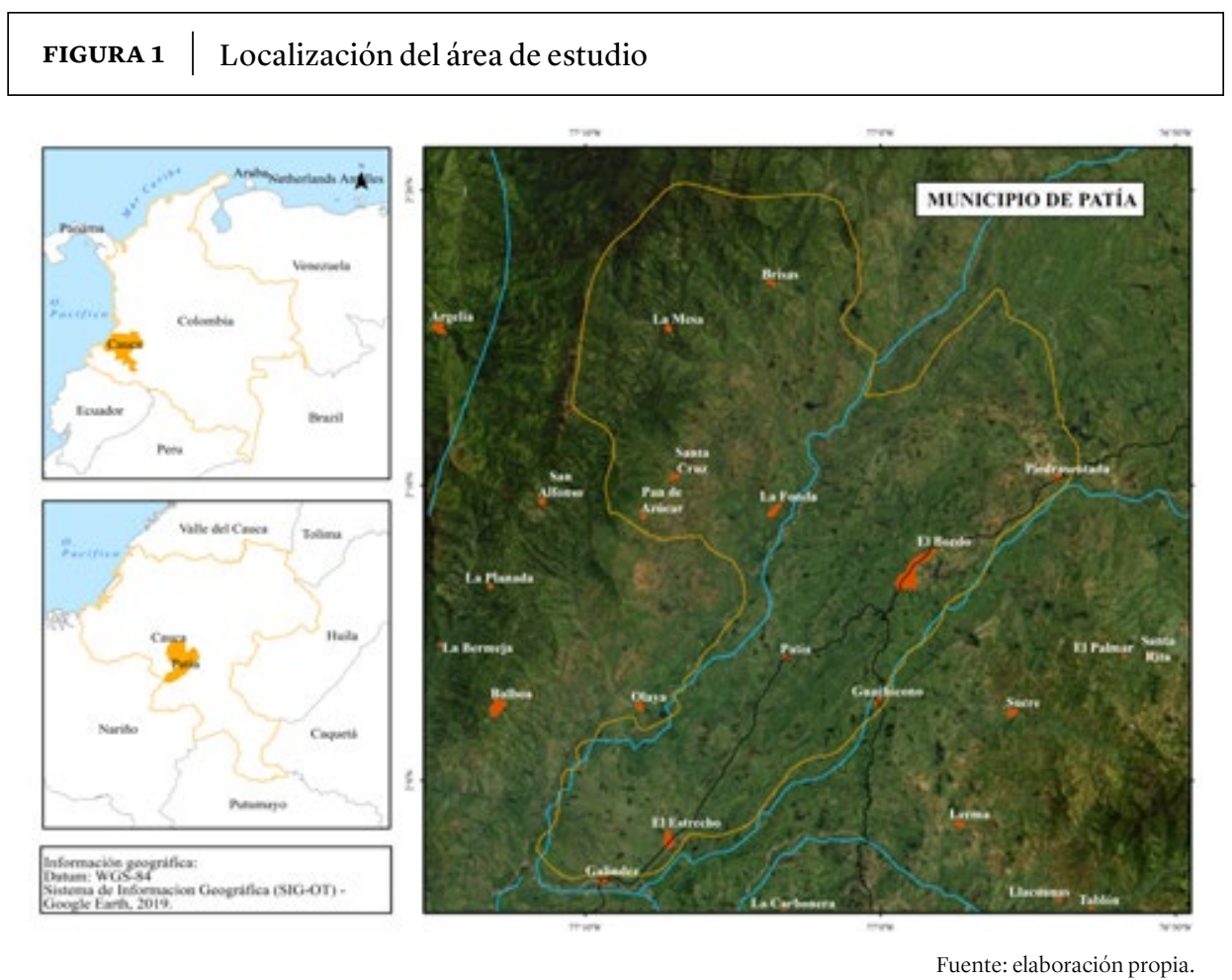

La elección del período se hizo debido a que la recuperación de tradiciones culturales comenzó a finales de los ochenta. Desde luego, esto no es agenciado exclusivamente por Adolfo Albán, ya que otros actores también han sido importantes. En este caso, vale la pena subrayar a las Cantaoras del Patía ${ }^{3}$, así como el Son del Tuno ${ }^{4}$ quienes han sido los grupos resultantes del proceso de recuperación de tradiciones culturales y los que mayor trayectoria han adquirido a nivel regional y nacional. Decla-

3. Las Cantaoras del Patía representan un símbolo para los habitantes del valle del Patía. Ellas cantan y oran: de ahí deriva su nombre "cantaoras".

4. Esta es una agrupación que canta bambucos patianos, originaria de la vereda El Tuno-Patía, y ha obtenido reconocimiento a nivel regional, producto de un trabajo continuo de más de dos décadas rescatando y difundiendo las tradiciones culturales del valle del Patía a través de la música. 
radas embajadoras de paz, ganadoras del premio nacional de cultura en 1994, y en el Festival Petronio Álvarez en 2009, las Cantaoras del Patía han ayudado a representar a este valle como un territorio donde se desarrollan experiencias socioculturales que dignifican las presencias de la gente negra del Patía en el plano regional y nacional. Sus canciones trascienden lo "tradicional" y se inscriben en lo político. Evidentemente, los cantos son contextuales, corresponden a unas geografías e historias con unas prácticas espaciales y socioculturales concretas. Sin embargo, los mensajes y conclusiones de sus canciones van más allá del territorio patiano, pues tienen que ver con la defensa del medio ambiente, la vida y la cultura, entre otros. El Son del Tuno es otro grupo representativo del Patía, y ha participado en numerosas ocasiones en el Festival Petronio Álvarez, así como en importantes encuentros musicales, tanto en Colombia como en el extranjero, llevando un importante mensaje de reafirmación y dignificación de la cultura patiana. En suma, las canciones de esta agrupación han logrado transmitir y sostener, en las generaciones de patianos, el interés por su música local.

Para finalizar, la estructura del documento es la siguiente: después de esta introducción, desarrollamos la perspectiva analítica a partir de la cual se dibujaron los contornos que definen nuestra investigación. Enseguida, está la entrevista al profesor Adolfo Albán en relación con su vínculo como actor con los procesos culturales en el valle del Patía; posteriormente, plasmaremos un análisis acerca de los procesos de recuperación de tradiciones culturales como prácticas de visibilidad e invisibilidad geográfica; $y$, por último, presentaremos unas reflexiones finales y las referencias bibliográficas.

\section{Perspectiva analítica}

Uno de los temas más discutidos en las últimas tres décadas por la teoría geográfica ha sido el de la escala geográfica. La idea de que esta es una construcción social se ha hecho constante y se ha repetido en la mayoría de los estudios (Brenner, 2001; Marston, 2000; Moore, 2018; Smith, 2002). De hecho, la escala geográfica se constituye en una potente categoría para comprender $y$, al mismo tiempo, complejizar procesos políticos, económicos, culturales y espaciales, entre otros. Lo anterior supondría que la escala es una construcción sociocultural, por lo que, en tanto construcción, presenta unas trayectorias que no la definen como una categoría fija y determinada, sino más bien fluida y altamente contingente (Moore, 2018).

Para el estudio de las escalas, los geógrafos han adoptado una perspectiva dualista: ontológica y epistemológica. En la primera, las escalas corresponden a una estructura geográfica construida en el marco de relaciones sociales, por lo tanto, 
son entidades reales (Gutiérrez-Puebla, 2001). Vista desde esta perspectiva, algunos territorios donde se sitúa espacialmente lo negro en los imaginarios de la colombianidad (Wade, 1997), como el Pacífico, Cartagena, Cali, el valle del Patía, entre otros, no serían marcos de análisis o discursos, sino estructuras socioespaciales que existen en el mundo real (Gutiérrez-Puebla, 2001), y se "establecen a través de la estructura geográfica de interacciones sociales" (Smith, 2002:141). Esta concepción ontológica de la escala supone, entonces, la "[dimensión] a partir del cual se ha de analizar la realidad" (Valenzuela, 2004: s.p.). En la segunda perspectiva, es decir, la epistemológica, el análisis e interpretación de las escalas se lee como lenguaje espacial discursivo. Por ende, las escalas representan concepciones ancladas en imaginarios desplegados por el ser humano para contextualizar y entender la realidad (Valenzuela, 2004). En definitiva, la escala, construida en una perspectiva epistemológica posibilita comprender que las escalas no son ubicaciones, localizaciones o áreas en sí, sino esquemas interpretativos para descifrar y describir realidades (Gibson-Graham, 2002).

La escala, como lo señala Herod (2008), puede ser explicada o descrita a partir de diferentes metáforas. Así, por ejemplo, una escalera podría representar las relaciones entre lo global, nacional, regional y local. A través de un círculo concéntrico podría representarse más o menos lo mismo. Otra metáfora es la de las muñecas rusas matrioska, en las que se puede apreciar una jerarquía anidada, y donde cada muñeca o escala es separada y puede considerarse de manera independiente (Herod, 2008). No obstante, la particularidad de estas es que solo pueden ser comprendidas en su totalidad con cada muñeca. A modo de ejemplo, una matrioska de nueve piezas solo será entendida en la articulación de la totalidad de ellas de menor a mayor. Este lenguaje de arriba-abajo, metafóricamente, nos lleva a pensar que lo global estaría en la muñeca más grande que contiene a las otras, esto es, la nacional, regional y local; sin embargo, no funcionaría al revés; es decir, en lo local no podríamos encontrar lo global o lo nacional (Herod, 2008).

Otra metáfora popularizada es la de conexiones en red, inspirada en la teoría del actor-red (Latour, 2008). El argumento se sintetiza de la siguiente manera: la complejidad del mundo no puede ser capturada en las ideas de niveles, esferas, escaleras, capas (Herod, 2008). Estas conexiones son como raíces enterradas y conectadas en diferentes estratos de la tierra y, metafóricamente, sirven para pensar las relaciones entre lo local y lo global, en tanto que no estarían separados (Herod, 2008).

La idea de la escala como red se ajusta al propósito de esta pesquisa. Sin embargo, nuestra compresión de la escala como red apunta a otro fin. No tiene que ver directamente con la relación entre lo local y lo global, lo cual es una preocupación de Herod (2008), pues la nuestra está asociada con la producción de redes escalares y cómo ellas 
generan unas prácticas de visibilidad e invisibilidad geográfica, en donde la primera representaría el nexo y la difusión de los procesos culturales a otros territorios; mientras que la segunda simbolizaría una red conectada con procesos difundidos a nivel de la municipalidad, corregimiento o vereda. No obstante, cuando cambia de escala una visibilidad local, dependiendo del contexto, derivaría en invisibilidad geográfica.

La red escalar, entonces, queda vinculada con la capacidad y posibilidad que tienen los agentes sociales (en este caso Adolfo Albán, las Cantaoras del Patía y Son del Tuno) de establecer y multiplicar las relaciones espaciales con otros actores sociales localizados en diferentes ámbitos territoriales. Es decir, nos referimos a las modalidades en que los agentes sociales, escalarmente -de forma ontológica y epistemológica-, configuran distintas conexiones articulando redes escalares. Esto nos lleva a pensar que la escala, como red, se convierte en un proceso político activo, mediado por relaciones de poder que construyen (Moore, 2018; Smith, 2002), constituyen y enredan (de "red") prácticas de visibilidades e invisibilidades geográficas. Las asociaciones de agentes, de la red escalar, tendrían una relación directa con el nivel de la visibilidad, pues el nexo con actores políticos, económicos, de consumo y culturales con injerencia en múltiples ámbitos territoriales (local, regional, nacional, global) implicaría un cambio en la jerarquía de la escala. Esto significa que su nivel de visibilidad e invisibilidad podría darse en términos municipales, departamentales o nacionales.

En contraposición a lo anterior, en un proceso cultural llevado a cabo únicamente por actores presentes en un ámbito territorial restringido (vereda, corregimiento, municipio), es probable que las visibilidades sean menores y, dependiendo del contexto de la municipalidad, posiblemente dicha visibilidad cuando se le cambie la escala -se pase a un plano regional o nacional- se convierta en invisibilidad geográfica, debido a que las toporrepresentaciones (pesos, símbolos y significados) asignadas (Avendaño-Arias, 2017) a ese territorio, en el proceso de producción de escala y en el imaginario territorial (Núñez, 2012), son mínimas.

Indiscutiblemente, las escalas nos permiten visualizar cómo determinados individuos o conglomerados sociales configuran el espacio a partir de redes y niveles. En efecto, entre mayor sea el número de redes en la conexión o jerarquía (local, regional o global), más amplia será la escala. Entonces, la escala se va definiendo como una práctica de visibilidades e invisibilidades geográficas; de hecho, en algunos de los relatos de importantes intelectuales, afrocolombianos o no, interesados en las dinámicas culturales de la gente negra, sus argumentos giran en relación a la permanente invisibilidad de los negros. De Friedemann (1993: 14) sostenía que "la invisibilidad en procesos socioculturales es una estrategia que ignora la actualidad, la historia y los derechos de grupos e individuos". Esto implica que: 
El paradigma de la invisibilidad, parte (...) haciéndonos olvidar la omnipresencia y multiplicidad, en la historia del país, de las categorizaciones de lo negro bajo formas de referencia a la raza, a la casta, al color, a la ascendencia, etc., nos hace olvidar también la omnipresencia y multiplicidad de las formas de discriminación y rechazo de lo negro. (Cunin, 2009: s.p.)

En el caso de Patía, por ejemplo, un municipio con una mayoría de población negra solamente pudo tener un alcalde negro a mediados de la década de los noventa. Estas dinámicas de invisibilidad de lo negro son resultado del racismo estructural sobre el cual se ha cimentado la sociedad colombiana desde la época colonial, y se expresa a partir del no reconocimiento de los aportes de la gente negra, incluso en los censos de población (Rodríguez-Morales, 2010). Si bien estamos de acuerdo con los argumentos que se refieren a la invisibilidad constante de las contribuciones de la gente negra a la construcción de la nación y, además, que las luchas del pueblo negro son escasamente reconocidas y visibilizadas en el discurso político, social y en la vida cotidiana en Colombia, es importante reconocer que la invisibilidad en que se dan estas situaciones son un problema geográfico y, por tanto, se inscriben con dinámicas asociadas a la producción de redes escalares.

En realidad, los aportes de intelectuales, activistas políticos, docentes y deportistas afrodescendientes, así como sus procesos culturales y sociales, entre otros, suelen ser reconocidos, pero su difusión se centra, por una parte, entre los mismos afrodescendientes y, por otra, en las localidades, municipalidades y departamentos de los cuales son originarios. Lo anterior se configura invisible porque, no obstante, se lugariza en la medida que salta de escala, se deslocaliza y construye visibilidades. Esto nos lleva enseguida a las preguntas que nos interesan: ¿cómo los procesos culturales en el valle del Patía generan prácticas de invisibilidad o visibilidad geográfica?, $\mathrm{y}$ ¿de qué manera las dinámicas de recuperación de tradiciones culturales en el valle del Patía han sido generadoras de redes escalares? Los anteriores interrogantes guiarán nuestra reflexión.

\section{Adolfo Albán y la recuperación de tradiciones culturales en el valle del Patía}

"Y algún día, un 29 de septiembre de 1988 voy llegando a este caserío de aquí de Patía...". De esta forma inicia Adolfo Albán (comunicación personal, 18.10.2018) el relato acerca de su primer contacto territorial con el valle del Patía. Este académico vallecaucano, formado como maestro en Bellas Artes en la Universidad Nacional de 
Colombia, con una maestría en Comunicación y Diseño Cultural de la Universidad del Valle y un Doctorado en Estudios Culturales Latinoamericanos en la Universidad Andina Simón Bolívar, sede Ecuador, nos describe su relación con el valle del Patía.

Aquel 29 de septiembre llegó a Patía debido a que coordinaba talleres de manualidades para pensionadas de CAJANAL 5 , en El Bordo ${ }^{6}$. Desde el corregimiento de Patía, iban "Ana Melia Caicedo; con Gloria, su hermana, y Teodolinda Torres" (Adolfo Albán, comunicación personal, 18.10.2018), ellas, a excepción de Gloria, serían parte del grupo de fundadoras de las Cantaoras del Patía. Por una muy buena coincidencia, Albán, "invitado por ellas, llego aquí [Patía], y están haciendo esa procesión a San Miguel Arcángel (...). Era una solemnidad impresionante” (Adolfo Albán, comunicación personal, 18.10.2018). Lamentablemente, las fiestas del patrono del pueblo estudiadas por Albán (2015) desaparecieron, pero ese viaje fue suficiente para que conociera otros patianos ilustres. Según Albán (comunicación personal, 18.10.2018), en medio del ritual ceremonial en honor a San Miguel Arcángel, llegó él, "tipo dos de la tarde, hacía un calor impresionante, un sol abrazador y había un personaje, de vestido de paño negro, de sombrero de fieltro alón, que se llamaba Roberto Carlos Obando".

Sin embargo, al arribar a Patía no había llegado en blanco, en tanto que había tenido el privilegio de leer-sin haber sido publicado todavía- lo que hoy es un clásico de la historia regional negra: Guerrilla y sociedad en el Patía (Zuluaga, 1993). Las palabras de Albán ahondan en que, enseguida de leer ese libro, tuvo una suerte de epifanía o revelación (término tomado de Dussel). Sus interrogantes giraban en torno a la pregunta de por qué no le enseñaron acerca de ese territorio en las clases de historia y geografía, ni en la escuela ni en el bachillerato. En palabras del entrevistado, él entendía estar en un "territorio que tiene una importancia en la historia de este país que no la enseñan (...). ¿Por qué esta sociedad de negros enclavados en un valle interandino nunca me la contaron?" (Adolfo Albán, comunicación personal, 18.10.2018), se cuestionaba al leer y coincidir con lo escrito por el historiador Francisco Zuluaga.

De este modo, Albán se fue interesando más por el Patía, y reconoce que tuvo "la fortuna de haber llegado con dos grandes maestras, Ana Melia Caicedo y Teodolinda Torres, y haber conocido al maestro Roberto Carlos Obando" (Adolfo Albán, comunicación personal, 18.10.2018), con quienes conversó y de quienes aprendió sobre la cultura patiana. Albán hace hincapié en su vínculo con el Patía más como proyecto de vida que propósito académico, lo cual le posibilita construir un sentido

5. La Caja Nacional de Previsión era una entidad que se encargaba de prestar seguridad social a los empleados del sector público.

6. El Bordo es la cabecera municipal de Patía-Cauca. 
de identidad colectivo como afrodescendiente, "porque empiezo a conocer cada vez más las profundidades del universo cultural. ¿Y esas profundidades uno cómo llega a ellas? Viviendo la vida cotidiana" (Adolfo Albán, comunicación personal, 18.10.2018). Su conexión con el Patía fue inmediata, de hecho, desde 1988 hasta 1993 estuvo viviendo en esas planicies, conociendo el día a día "y ahí es cuando iniciamos el proyecto de recuperación de tradiciones culturales, y eso es lo que me va a llevar al lado de las cantaoras y el grupo de músicos del Tuno; es a ir conociendo muchos más detalles de la cultura de este valle interandino" (Adolfo Albán, comunicación personal, 18.10.2018).

Con el maestro Roberto, así como con las profesoras Ana Melia y Teodolinda, Adolfo Albán enfatiza que aprendió con él y ellas, quienes le ayudaron a conectarse no solo con el territorio como espacio físico-afectivo, sino con otros actores sociales. Este proceso de engancharse con el territorio y construir unas relaciones de afectividad con la gente se puede comprobar fácilmente en la cantidad de entrevistados, que figuran en su tesis de maestría sobre las migraciones y adaptaciones culturales de los patianos en el Valle del Cauca, concretamente en Cali. Albán insiste en que nunca publicaría las grabaciones hechas con estas mujeres, muchas de ellas ya fallecidas, pues al momento de llegar él al Patía ya eran de la tercera edad.

De las conversaciones, una de las cosas que nos comparte es que las mujeres mayores le decían: "la cultura de nosotros se está perdiendo, (...) los bailes y la música de antes ya no se toca, los cantos ya no se cantan, ya no enterramos a los muertos como se enterraban, y la comida de antes ya no se come" (Adolfo Albán, comunicación personal, 18.10.2018). La tesis de Albán (1999) es que, con la llegada de la energía eléctrica y los tocadiscos, la música y bailes tradicionales como el bambuco en sus distintas versiones empezaron a ser desplazados por la música afroantillana, los pasillos ecuatorianos y los boleros. Frente a la comida, una causa identificada por él de la desaparición de los platos típicos es la revolución verde. Este paquete modernizador es un simplificador del paisaje cultural, el cual, para el valle del Patía, implicó la implementación de monocultivos y la desaparición de la diversidad de las fincas campesinas negras (Albán, 2007; Mosquera-Vallejo, 2019), con efectos concretos en la gente; por ejemplo, las comidas que se "hacían con lo producido en las parcelas desapareció (...). Todas esas recetas tradicionales eran parte del universo de sentido, del paladar de esta sociedad, el capitalismo con su proyecto productivo 'mono' las había desplazado" (Adolfo Albán, comunicación personal, 18.10.2018). Además, con la frase "los muertos ya no se entierran como antes" hace referencia a que los cantos, arrullos de angelitos, salves y letanías ya no se cantaban, pues la Iglesia había expulsado de la ritualidad los cantos tradicionales (Albán, 2007; Quintero, 2010). 
"Empiezo a entender qué ha pasado en este valle del Patía en términos políticos" (Adolfo Albán, comunicación personal, 18.10.2018). Esto lo ha llevado a asumir un lugar de enunciación anclado en el pensamiento crítico, donde su enfoque teórico, para entender estas planicies, es el giro u opción decolonial, desde la cual se busca interrumpir los relatos celebratorios y eurocéntricos de la modernidad o, dicho de otro modo, "las múltiples articulaciones de la colonialidad del poder en la re-producción del sistema mundo moderno/colonial" (Restrepo, 2005: 16). Sin embargo, su práctica es decolonial. En este sentido, y después de comprender cómo el Patía ha sido objeto de estigmatización en diferentes períodos históricos, Albán dice que eso le lleva a tomar una "posición política, a este valle del Patía hay que visibilizarlo, y desestigmatizarlo" (comunicación personal, 18.10.2018).

La configuración de una red escalar en el marco de la recuperación de tradiciones culturales en el Patía ha tenido un actor central: Virgilio Llanos, de la vereda El Tuno, y líder de la agrupación Son del Tuno. En esa vereda se ha desarrollado, con más hincapié, la recuperación de tradiciones. A Albán lo sorprendió que en El Tuno "todos son músicos". Su conexión con ese lugar, así como los lazos de amistad, afectividad y compadrazgo generados allí ayudaron en la co-construcción del proceso musical de Son del Tuno. Igualmente, en el corregimiento de Patía, las redes que fue elaborando con diferentes personalidades del lugar posibilitaron su participación y, con ello, el apoyo en la consolidación de las Cantaoras del Patía. Esos años (desde finales de los ochenta hasta comienzos de los noventa) los vivió de "la caridad pública en el valle del Patía. Eso le permitió dedicarse al proceso cultural. Desayunaba y quedaba listo para el proceso. A seguir trabajando por esto, dinamizando más" (Adolfo Albán, comunicación personal, 18.10.2018). Adolfo Albán no define su trabajo como el de un gestor o animador cultural, sino que señala, para finalizar e inspirado en una frase de Jesús Martin Barbero, que se ha dedicado a ser un "agitador cultural"; es decir, a impedir que los procesos culturales decaigan.

\section{Visibilidades e invisibilidades en el valle del Patía: Cantaoras de Patía y Son del Tuno}

La entrevista nos permite entender, en parte, cómo ha sido el proceso de agenciamiento de las dinámicas culturales en el valle del Patía. Esta agencia ha tenido una serie de resultados manifestados en la recuperación de tradiciones culturales en el campo de la música, comida y los bailes, permitiendo la difusión de los procesos culturales desarrollados en estas planicies. La radio, los CD y, en los últimos años, la internet, junto con unas dinámicas de apropiación más fuertes desarrolladas por los 
migrantes patianos, en diferentes ciudades del país, han logrado una mayor visibilidad de esta cultura. Sin embargo, antes de profundizar en esto, es necesario aclarar a qué nos referimos, conceptualmente, con los términos visibilidad e invisibilidad.

Según el diccionario de la Real Academia de Lengua Española (RAE), la visibilidad es: 1) una cualidad de lo visible, es decir, de aquello que es posible ver, o se refiere a; 2) mayor o menor distancia a que, según las condiciones atmosféricas, pueden reconocerse o verse los objetos. La invisibilidad sería la contraposición de la visibilidad, su reverso, es decir, aquello que no puede ser visto. De acuerdo con nuestra lectura de la escala, es válido preguntarse cuál es la relación entre las redes escalares en los procesos culturales desarrollados en el valle del Patía y las prácticas de visibilidad e invisibilidad geográfica. Una posible respuesta a este interrogante podría llevarnos a entender la invisibilidad como práctica de visibilidades lugarizadas, esto es, prácticas ancladas al lugar; mientras que la visibilidad articula prácticas deslocalizadas, es decir, deslugarizadas. Esto supondría imaginar una escala en la que intervienen dinámicas que la construyen más allá de su localización, e implicaría concebirla como un proceso que, de manera simultánea, se enreda con otras redes espacializadas de relaciones sociales (Herod, 2008).

Podríamos pensar que la escala es más similar a un conjunto de madrigueras de gusanos o raíces de árboles que se entrelazan a través de diferentes estratos de suelo. Aunque es posible reconocer diferentes escalas (al igual que es posible pensar en las madrigueras de gusanos o las raíces de los árboles que penetran en diferentes estratos del suelo, con algunas profundizando más que otros), es difícil determinar exactamente dónde termina una escala y otra comienza y no es necesariamente posible pensar en términos jerárquicos acerca de la escala. Esta es una manera bastante diferente de conceptualizar la escala. Entonces ya no estamos hablando de escala en términos de espacios delimitados o las métricas de las jerarquías claramente definidas del espacio. (Herod, 2008: 230)

La forma de imaginar la escala y las metáforas usadas para describirla impacta el modo en que política y socialmente nos asumimos en nuestros territorios (Herod, 2008). Teniendo en cuenta esta consideración, hemos concebido para nuestra pesquisa la escala como una red. Pensar los procesos culturales desarrollados en el valle del Patía como una red nos permite comprender cómo estos se despliegan en lo local, a partir del contacto con diferentes agentes sociales que van generando una suerte de redes espacializadas de interacción social. Ellas, inicialmente, representarían una situación "empírica" que podría asociarse con la escasa difusión de las tradiciones culturales. Con lo local, nos referimos, por ejemplo, a la poca expansión de la música tradicional, concentrada en algunas veredas del valle del Patía, como El Tuno. Sin embargo, esta es una localidad que contenía lo regional del Patía, pues el bambuco 
era la música escuchada allí hasta la década de los sesenta y que fue desapareciendo, especialmente con la llegada de la salsa, boleros y pasillos ecuatorianos, pero en esa vereda se mantuvo la tradición musical. En definitiva, de lo señalado por Albán en la entrevista se puede interpretar que, en el caso del Son del Tuno, su música era similar a los drenajes del Patía en temporada de sequía, en donde el agua solamente corría en determinados lugares, es decir, era un bambuco lugarizado.

Junto con lo anterior, la metáfora de la escala como red que entrama múltiples conexiones nos muestra una modalidad que evidencia las formas de construcción de la escala de dos formas: por un lado, unas invisibilidades que lugarizan las expresiones culturales a partir de la escasa multiplicidad de actores sociales que intervienen; y, por otro, unas visibilidades en donde se deslocaliza la expresión cultural y se vincula con diferentes actores sociales, precisamente producto de la heterogeneidad de los mismos. Es importante destacar que las invisibilidades y visibilidades están mediadas por relaciones de poder entre los diferentes actores sociales, las cuales coadyuvan a establecer estas categorías en la recuperación de tradiciones culturales.

$\mathrm{Al}$ respecto, Marston (2000) describe el trabajo desarrollado por John Agnew, acerca de la importancia de la escala en los partidos políticos italianos, para la negociación de las relaciones de poder. Otro ejemplo lo ofrece Adams (1996), quien analiza cómo las telecomunicaciones no solo reorganizan la información y las ideas en el espacio, sino que también alteran los equilibrios en las relaciones de poder. Sostiene que, si bien es cierta la centralización del poder y el capital, los grupos subalternos pueden lograr algunos objetivos al explotar la infraestructura de telecomunicaciones existente. Para Adams (1996), esta táctica es geográfica, pues dichos grupos se niegan a aceptar los sistemas de poder establecidos. En definitiva, y de modo análogo, en la experiencia que estamos analizando se desarrolla una estrategia geográfica cuyo propósito ha sido revitalizar los procesos culturales al interior del valle y difundirlos en diferentes espacios de la geografía nacional.

La recuperación y visibilización de las tradiciones culturales han sido articuladas por el profesor Albán, junto con otros actores localizados en diferentes lugares de las redes espacializadas de relaciones sociales. De esta forma, lo descrito por Adolfo Albán en su narración acerca de cómo fue estableciendo vínculos con diferentes actores en el valle del Patía, lo que en palabras de él "permitió dedicarse al proceso cultural”, representa una muestra de cómo son agenciadas las escalas. De hecho,

(...) el resultado de este trabajo fue la conformación del Grupo de Cantaoras de Patía y el Grupo de Músicos de El Tuno (...), quienes constituyeron el Grupo de Recuperación de Tradiciones Culturales del Valle del Patía, dándose a la tarea de recuperar, preservar y difundir la cultura patiana y dar a conocer los valores regionales de una zona olvidada por el departamento y la nación. (Albán, 1999: 78) 
Estos grupos se convirtieron en colectivos e, inicialmente, fueron recopilando en cada una de las veredas los elementos culturales que ellos consideraban que se estaban perdiendo. Lo anterior nos lleva a establecer que los músicos del Tuno y las Cantaoras del Patía construían una suerte de relaciones sociales con otros actores del valle del Patía y, a través de la "agitación cultural", es decir, el movimiento del proceso de recuperación de tradiciones culturales, crearon redes en todo el espacio cultural patiano. Ellas, en un principio, se configuraban bajo unas prácticas de invisibilidad geográfica, en tanto que los saberes y expresiones culturales estaban perdiéndose o eran conocidos por pocos agentes, y su difusión espacial se localizaba solo en algunos corregimientos de las planicies del Patía. El propósito era construir un régimen de visibilidad, a partir de los procesos desarrollados al interior del valle del Patía. Así, por ejemplo:

Con la comunidad del Tuno, caracterizada por la presencia de numerosos músicos y el encuentro con Gentil Rodríguez, un eximio violinista hoy ya desaparecido, nos dimos a la tarea de trabajar con el bambuco viejo o bambuco patiano investigando sus letras y su ritmo, así como también la forma de bailarlo. Con este grupo fuimos recorriendo corregimientos y veredas del Valle del Patía llevando esta música para que los mayores recordaran sus letrasy sus formas de bailar y para que las nuevas generaciones fueran conociendo y reconociendo su cultura musical propia. Las fiestas tradicionales del Valle del Patía que se celebran el 15 de agosto en honor a Nuestra Señora del Tránsito fueron y siguen siendo el escenario privilegiado para dar a conocer este bambuco, al igual que las festividades patronales y festivales que se realizan en cada comunidad. (Albán, 2013: 466-467) ${ }^{7}$

Asimismo, entre más poderosos o mayor sea el número de agentes involucrados en una dinámica cultural, los procesos culturales resultantes tendrán una mayor visibilidad. De esta forma:

La cultura patiana empezó a salir a diversas partes del país, ya no para migrar y quedarse lejos del territorio patiano, sino para viajar y retornar nuevamente, retroalimentándose de las experiencias y continuar el proceso de autorreconocimiento de los valores culturales que han hecho importante a estas comunidades. (Albán, 1999: 79) ${ }^{8}$

Como resultado de lo anterior, se fue dando un cambio en las redes escalares, manifestado, en primera instancia, en la producción de los trabajos musicales de las Cantaoras del Patía, Son del Tuno y los grupos de danza, y posteriormente en

7. Cursivas añadidas.

8. Cursivas añadidas. 
la gastronomía, sobre todo a partir del kumis patiano. A manera de ejemplo, una muestra de las visibilidades geográficas creadas como consecuencia de procesos inicialmente generados en el valle del Patía y que ahora involucran a más actores es el caso de las Cantaoras del Patía. Solo basta con entrar a un buscador como Google y escribir las palabras "Cantaoras del Patía" para observar la cantidad de resultados: 3890 , en 0,42 segundos. Los resultados muestran entrevistas en diarios de circulación regional como El País, de Cali, o nacional, como El Tiempo, así como blogs y documentales sobre ellas. Una situación similar ocurre cuando se busca algunos de los trabajos discográficos, especialmente los más antiguos, en plataformas virtuales como YouTube, en donde algunas canciones, por ejemplo, "Pajarillo" registran más de 20.000 visitas. Esto evidencia, por una parte, cómo la comunicación en internet puede ser usada para compartir información e ideas a través del espacio, alterando, en ocasiones, las relaciones de poder (Adams, 1996); y, por otra, cómo la estrategia de visibilización o cambio de escala supone mayor alcance de los procesos y dinámicas desarrolladas por comunidades afrodescendientes en el valle del Patía.

El mismo ejercicio de búsqueda realizado con las Cantaoras fue hecho con Son del Tuno. Encontramos los siguientes resultados: con las palabras clave "Son del Tuno" se obtuvieron alrededor de 22.700 .000 resultados. No obstante, debe tenerse en cuenta que esto es consecuencia de, primero, que la palabra "Tuno" acoge una pluralidad mayor de significados que el término "Cantaoras", pues, además, se refiere a nombres de municipalidades, plantas, disfraces, entre otras; y, segundo, algunas canciones de Son del Tuno tienen un enfoque más comercial que las de las Cantaoras de Patía; prueba de ello son algunos de los videos de las canciones de esta agrupación vistos en YouTube, los cuales tienen más de 120.000 reproducciones.

El Son del Tuno también ha tenido un proceso de agencia y cambio en las redes escalares en parte a través del trabajo cultural de Adolfo Albán quien ha sedimentado experiencias, construido trayectorias y visibilizado la agrupación. Este grupo de bambuco patiano,

(...) que lleva ya 20 años de trabajo ininterrumpido, les brindó a estas comunidades la oportunidad de volver sobre su ancestralidad, sus raíces, reivindicarse étnico-territorialmente, fortalecer sus identidades y afianzar una dignidad pisoteada y mancillada por las élites blanco-mestizas de esta región del país (...), el "Son del Tuno" continúa interpretando las canciones tradicionales y componiendo nuevos bambucos que actualizan este ritmo y lo contextualiza en un presente aún lleno de carencias y dificultades, llevándolo por diferentes regiones de Colombia. Con tres producciones discográficas, esta agrupación musical ha contribuido a que el bambuco patiano se interprete y se baile garantizando con ello su permanencia. Son dos las generaciones de músicos que han hecho parte de este grupo, la actual conformada en su mayoría por los hijos de 
aquellos que a finales de la década de los años 1980 (...) se decidieron a que su cultura musical no pereciera en las oscuras profundidades del olvido. (Albán, 2013: 468)

Además de la agrupación Son del Tuno y de las Cantaoras de Patía, otros grupos de violinistas, escuelas de violines y grupos de danza se han convertido en los dinamizadores de los procesos socioculturales en el valle del Patía. Un último ejemplo, aunque a veces más silencioso que la música, es la gastronomía. En esta se han recuperado platos como el guampín, el cual ha sido objeto de diferentes reconocimientos en distintas instancias como el festival gastronómico de Popayán. Éxito mayor ha tenido el kumis patiano, cuya difusión ha traspasado el espacio cultural del valle.

Asimismo, es importante reconocer, que:

Los procesos de re-vitalización cultural que las comunidades del Pacífico colombiano, unidas a las oleadas migratorias hacia las principales ciudades del país, han producido, también la migración de los ritmos que cambiaron el paisaje acústico de ciudades como Cali, Bogotá y Medellín y permitieron la llegada de estas músicas a centros culturales, emisoras y a las casas disqueras, generando una dinámica importante de visibilización musical (...). Espacios culturales para el encuentro, difusión y comprensión de estas músicas aparecieron como consecuencia de la exigencia de agrupaciones con alta calidad interpretativa -no necesariamente académica- que demandaban oportunidades para su expresión, ejemplo de ello para el caso del sur occidente colombiano es el Festival Petronio Álvarez en Cali con una trayectoria reconocida a nivel nacional. (Albán, 2013: 465) ${ }^{9}$

Lo señalado en este análisis es resultado de un proceso de producción de redes escalares hacia "el adentro" que, en el marco de las relaciones, interacciones e intercambios y procesos, se vincula con "el afuera" de forma diferenciada (Mosquera-Vallejo, 2018). De esta manera, cuando la práctica cultural (música o gastronomía) hacia adentro se enreda de múltiples maneras con diferentes actores y se hace agencia, se convierte en una práctica hacia el afuera, que deja de ser considerada simple folclor o expresión musical reducida a ámbitos espaciales restringidos. En este sentido, el bambuco patiano se convierte en un proceso de producción de redes escalares, a partir del cual el valle del Patía y la gente negra del Patía dejan de ser actores reducidos espacialmente y pueden entrar a configurar unas visibilidades que implicarían su reconocimiento como actores sociales importantes dentro del ámbito de las dinámicas culturales negras y no negras en Colombia.

9. Cursivas añadidas. 


\section{Reflexiones finales}

Este análisis acerca de la escala como construcción de redes espacializadas, que producen unas prácticas de visibilidades e invisibilidades geográficas, en los procesos culturales de la gente negra en el valle del Patía, situado desde la perspectiva de escala en geografía humana, nos llevó a entender que para visibilizar las luchas afrodescendientes, es decir, ampliar la red de actores involucrados en el marco de una relación social, no solo basta con reconocer que estos actores sociales producen espacio, sino que, además, producen escala (Smith, 2002).

En efecto, los procesos sociales afrocolombianos, como las recuperaciones de tradiciones culturales, la defensa del territorio, el Festival Petronio Álvarez y el Festival San Pacho, entre otros, representan luchas de escala. Ellas son ontológicas, construidas en el marco de relaciones y, al mismo tiempo, epistemológicas, pues reflejan y se organizan de acuerdo con los sentidos de mundo de la gente negra. Analizar los procesos culturales de la gente negra y describir los aportes de actores sociales a estas dinámicas como singulares formas de producir redes escalares supone reconocer que los ámbitos donde se despliegan las tensiones tienen una poderosa base para desafiar a poderes hegemónicos. La activista, defensora de derechos humanos y ganadora del premio Goldman -considerado el "Nobel" del medio ambiente-, Francia Márquez Mina, podría representar un ejemplo de cómo construir escala, es decir, redes espacializadas que le han dado una serie de visibilidades geográficas a la lucha que representa, y a ella como agente social.

La siguiente descripción hecha por la educadora y cantaora Ana Melia Caicedo puede ser entendida como una forma de producir redes espacializadas y hacer escala:

Nosotros venimos trabajando alrededor de la cultura. Esa es como otra arma que hemos utilizado para que, valiéndonos de eso, las personas nos agrupemos, nos organicemos y trabajemos por el progreso y el desarrollo de esto. Ya la gente viene entrando en el rol de trabajar, a partir de la cultura, otros aspectos de la vida. Existe un grupo de personas, aun no muy numeroso que han decidido no salir de la región, sino, quedarse para contribuir con su desarrollo. Por allí estamos jalonando cosas nuevas, que han generado progreso en la educación, el trabajo comunitario y vamos ganando espacios a nivel de la región, del departamento y del mismo país. Ya han empezado muchos a poner los ojos en Patía y a conocerlo por la cultura. Un 10 de abril de 1989 aquí debajo de la ceiba, hicimos el compromiso con el grupo de recuperación de tradiciones culturales, de difundir nuestra cultura y hasta ahora lo estamos cumpliendo. Hemos llevado nuestro mensaje a todas partes de Colombia en universidades, plazas públicas, en numerosos eventos e inclusive hemos incursionado en los espacios de la política para participar en los órganos decisorios del poder. (Caicedo, como se citó en Albán, 1999: 79-80) 
Este relato de la profesora Ana Melia-como se le conoce en el Patía- nos sirve de síntesis para lo que hemos sostenido a lo largo de este texto. En efecto, "ellas han trabajado alrededor de la cultura", pero esta ha sido usada como otra arma para agenciar múltiples procesos a nivel local. Apoyados en el "arma" como instrumento político que representa la cultura, las personas se agruparon, organizaron y trabajaron; y elaboraron una red conformada a partir del trabajo comunitario la cual les permitió que "jalonaran cosas nuevas". Una de ellas fue la construcción del Colegio Capitán Bermúdez, en el corregimiento de Patía. Con el compromiso de recuperar sus tradiciones culturales, "difundir nuestra cultura", han ido "ganando espacios a nivel de la región, del departamento y del mismo país".

Además de esto, el proceso cultural que Adolfo Albán fue construyendo con las educadoras y con el grupo del Son del Tuno permitió a ambas agrupaciones llevar el mensaje del bambuco patiano "a todas partes de Colombia en universidades, plazas públicas, en numerosos eventos". Para ilustrar mejor, ellas han sido ganadoras del Premio Nacional de Cultura, en 1994, y en el Festival Petronio Álvarez, en el año 2009; y han tenido numerosas participaciones en este evento, lo cual es una prueba de que el grupo de Cantaoras del Patía ha logrado lo propuesto hace unas décadas atrás: difundir la cultura patiana.

Lo descrito en este trabajo permite apreciar cómo los procesos culturales articulan prácticas de visibilidad e invisibilidad geográfica. La generación de redes escalares puede ser articulada de múltiples maneras. El apoyo de actores como Albán y otros ha ayudado a ofrecer las herramientas organizativas y, en algunos casos, hasta de instrumentos musicales, con el fin de que los procesos culturales en el valle del Patía no decaigan, de manera que uno de los efectos de esto ha sido que en otras comunidades de estas planicies, donde también hay músicos, han comenzado a agenciar sus procesos culturales a partir de dinámicas propias; ejemplo de esto son las agrupaciones Son de Mulaló, Son de Capellanía o Son de Patanguejo, las cuales han tenido notables éxitos $\mathrm{y}$, al mismo tiempo, representan al espacio cultural de las comunidades negras del valle del Patía. De esta manera, se muestra lo poderoso que puede ser el agenciamiento de los procesos en términos de redes escalares como visibilidad geográfica, pues las organizaciones culturales locales, a partir de sus creatividades y recursos, se movilizan en la búsqueda de objetivos que tienen como propósito la ampliación de sus prácticas de visibilidad geográfica.

Para finalizar, es necesario reconocer que lo visible y lo invisible se co-construyen; y, bajo esa perspectiva, lo invisible lugarizado no debe ser entendido, necesariamente, como lo auténtico, tradicional e inmóvil; mientras que lo visible, al estar en múltiples áreas y niveles, articularía lo dinámico productivo (Mosquera-Vallejo, 2018). En realidad, ambos se constituyen, enredan e imbrican, ordenan y desordenan 
configurando entramados en los que el cambio de las redes escalares-visibilidad e invisibilidad-se logra a partir de agentes que desplazan y revitalizan procesos que adquieren significatividad espacial y performatividad política.

\section{Referencias}

Adams, Paul (1996). Protest and the Scale Politics of Telecommunications. Political Geography, 15(5), 419-441. https://doi.org/10.1016/0962-6298(95)ooo88-7

Albán, Adolfo (1999). Patianos allá y acá: migraciones y adaptaciones culturales 1950-1997. Popayán: Fundación Pintáp Mawá.

Albán, Adolfo (2007). Tiempos de sangoy guampin:transformaciones gastronómicas, territorialidad y re-existencia sociocultural en comunidades afrodescendientes de los valles interandinos del Patía (sur de Colombia) y Chota (norte del Ecuador), siglo XX (Tesis doctoral). Universidad Andina Simón Bolívar, Área de Letras y Estudios Culturales, Quito, Ecuador.

Albán, Adolfo (2013). Pedagogías de la re-existencia. Artistas indígenas y afrocolombianos. En Pedagogías decoloniales: prácticas insurgentes de resistir, (re) existir y (re) vivir (pp. 443-468), editado por Catherine Walsh. Quito: Abya-Yala.

Albán, Adolfo (2015). Sabor, poder y saber: comida y tiempo en los valles afroandinos del Patía y Chota-Mira. Popayán: Universidad del Cauca.

Amador-Jimenez, Mónica (2010). La incesante diáspora africana: afrocolombianas solicitantes de asilo en el norte chileno. Nomadías, 12, 89-103. https://doi.org/10.5354/o7190905.2010 .15257

Arboleda, Santiago (2011). Le han florecido nuevas estrellas al cielo: suficiencias íntimas y clandestinización del pensamiento afrocolombiano (Tesis doctoral). Universidad Andina Simón Bolívar, Área de Letras y Estudios Culturales, Quito, Ecuador.

Avendaño-Arias, Johan Andrés (2017). Representaciones socio-espaciales (toporrepresentaciones) de Bogotá: perspectivas de la (in)seguridad. Sociedad y Economía, 33, 55-75. https:// doi.org/10.25100/sye.voi33.5624

Brenner, Neil (2001). The Limits to Scale? Methodological Reflections on Scalar Structuration. Progress in Human Geography, 25(4), 591-614. https://doi.org/10.1191/030913201682688959

Caicedo, José (2013). A mano alzada... Memoria escrita de la diáspora intelectual afrocolombiana. Popayán: Sentipensar. 
Cunin, Elisabeth (2003). El negro, de una invisibilidad a otra: permanencia de un racismo que no quiere decir su nombre. Palobra, 5, 1-12. https://doi.org/10.32997/2346-2884-vol.4num.4-2003-929

Cunin, Elisabeth (2009). El negro, de una invisibilidad a otra: permanencia de un racismo que no quiere decir su nombre. Proceso de Comunidades Negras de Colombia. Recuperado de https://renacientes.net/blog/2009/o8/16/el-negro-de-una-invisibilidad-a-otra-permanencia-de-un-racismo-que-no-quiere-decir-su-nombre/

De Friedemann, Nina (1993). Negros en Colombia: identidad e invisibilidad. América Negra, 3, 25-35.

Escobar, Arturo (1999). El final del salvaje: naturaleza, cultura y política en la antropología contemporánea. Bogotá: ICAN.

Gibson-Graham, Julie Katherine (2002). Beyond Global vs. Local: Economic Politics Outside the Binary Frame. En Geographies of Power: Placing Scale (pp. 25-6o), editado por Andrew Herod; Melissa W. Wright. Oxford: Blackwell.

Gil-Hernández, Franklin (2015). "Estar en el mundo de los blancos": las tensiones entre clase y raza en las experiencias de personas racializadas como negras en sectores medios en Bogotá D. C. Revista de Antropología, 58(2), 263-287. https://doi.org/10.11606/2179-0892. ra.2015.124243

Gutiérrez-Puebla, Javier (2001). Escalas espaciales, escalas temporales. Estudios Geográficos, 62(242), 89-104. http://dx.doi.org/10.3989/egeogr.2001.i242.295

Herod, Andrew (2008). Scale: The Local and Global. En Key Concepts in Geography (pp. 217-235), editado por Sarah Holloway; Stephen Rice; Gill Valentine; Nick Clifford. London: SAGE.

Hurtado-Saa, Teodora (2008a). Los estudios contemporáneos sobre población afrocolombiana y el dilema de la producción del conocimiento "propio". Revista CS, 2, 75-99. https://doi. org/10.18046/recs.i2.412

Hurtado-Saa, Teodora (2008b). Movilidades, identidades y sexualidades en mujeres afrocolombianas migrantes en Europa: el caso de las italianas. En Raza, etnicidady sexualidades. Ciudadanía y multiculturalismo en América Latina (pp.343-375), editado por Peter Wade; Fernando Urrea; Mara Viveros. Bogotá: Universidad Nacional de Colombia.

Latour, Bruno (2008). Reensamblar lo social: una introducción a la teoría del Actor-Red. Buenos Aires: Manantial.

Lozano, Betty Ruth (2016). Tejiendo con retazos de memorias insurgencias epistémicas de mujeres negras/afrocolombianas. Aportes a un feminismo negro decolonial (Tesis doctoral). Universidad Andina Simón Bolívar, Área de Letras y Estudios Culturales, Quito, Ecuador. 
Marston, Sallie (2000). The Social Construction of Scale. Progress in Human Geography, 24(2), 212-242. https://doi.org/10.1191/030913200674086272

Moore, Adam (2018). Repensar a escala como uma categoria geográfica: da análise para a prática. GEOgraphia, 2O(42), 1-24. https://doi.org/10.22409/GEOgraphia2018.v20i42.a13829

Mosquera-Rosero, Claudia; León-Díaz, Ruby (2009). Acciones afirmativas en Colombia: entre paradojasy superposiciones de lógicas políticasy académicas. En Acciones afirmativas y ciudadanía diferenciada étnico-racial negra, afrocolombiana, palenquera y raizal. Entre bicentenarios de las Independencias y Constitución Política de 1991 (pp. I-XXVI). Bogotá: Investigaciones CES/Universidad Nacional de Colombia.

Mosquera-Vallejo, Yilver (2018). Escalas geográficas e identidades territoriales: trayectorias desde las comunidades negras del valle del Patía. Geographia Meridionalis, 4(2), 126-144. http://dx.doi.org/10.15210/gm.v4i2.14484

Mosquera-Vallejo, Yilver (2019). Espacios expoliados, paisajes esquilmados: cambios en el paisaje del valle del Patía (1964-2014). En Las geografias del neoliberalismo en América del Sur. Ensayos descriptivos, críticosy necesarios (pp.90-123), editado por Daniel Santana-Rivas; Voltaire Alvarado-Peterson; Rodrigo Hidalgo-Dattwyler. Santiago de Chile: Serie Geolibros.

Múnera, Alfonso (1998). El fracaso de la nación: región, clase y raza en el Caribe colombiano (1717-1821). Bogotá: Ancora.

Muñoz, Paloma (2004). El bambuco patiano: evidencia de lo negro en el bambuco. En Estudios afrocolombianos aportes para un estado del arte (pp. 325-333), compilado por Axel Rojas. Popayán: Universidad del Cauca.

Núñez, Andrés (2012). El país de las cuencas: fronteras en movimiento e imaginarios territoriales en la construcción de la nación. Chile, siglos XIX y XX. Scripta Nova, XVI(418). Recuperado de http://www.ub.edu/geocrit/sn/sn-418/sn-418-15.htm

Oslender, Ulrich (2002). Espacio, lugar y movimientos sociales: hacia una "espacialidad de resistencia”. Scripta Nova, VI(115). Recuperado de http://www.ub.edu/geocrit/sn/sn-115.htm

Oslender, Ulrich (2003). "Discursos ocultos de resistencia”: tradición oral y cultura política en comunidades negras de la costa pacífica colombiana. Revista Colombiana de Antropología, 39, 203-235. Recuperado de http://www.scielo.org.co/scielo.php?script=sci_arttext\&pi$\mathrm{d}=$ So $486-65252003000100007 \& \operatorname{lng}=\mathrm{en} \& \operatorname{tn} \mathrm{ln}=\mathrm{es}$

Oslender, Ulrich (2008). Comunidades negras y espacio en el Pacífico colombiano: hacia un giro geográfico en el estudio de los movimientos sociales. Bogotá: ICANH/Universidad Colegio Mayor de Cundinamarca.

Quintero, Juan (2010). Religiosidad afropatiana funerales de angelitos: arrullos (Trabajo de grado). Pontificia Universidad Javeriana, Facultad de Ciencias Sociales, Bogotá, Colombia. 
Restrepo, Eduardo (2005). Políticas de la teoría y dilemas en los estudios de las colombias negras. Popayán: Universidad del Cauca.

Restrepo, Eduardo; Rojas, Axel (2008). Afrodescendientes en Colombia: compilación bibliográfica. Popayán: Universidad del Cauca.

Rodríguez-Morales, Margarita María (2010). La invisibilidad estadística étnico-racial negra, afrocolombiana, raizal y palenquera en Colombia. Trabajo Social, 12, 89-99. Recuperado de https://revistas.unal.edu.co/index.php/tsocial/article/view/18970

Rojas, Axel (2004). Presentación. En Estudios afrocolombianos. Aportes para un estado del arte (pp. 7-17). Popayán: Universidad del Cauca.

Rojas, Axel (2011). Interculturalidad el problema de las relaciones entre culturas (Tesis de maestría). Pontificia Universidad Javeriana, Facultad de Ciencias Sociales, Bogotá, Colombia.

Ruiz-Serna, Daniel (2017). El territorio como víctima. Ontología política y las leyes de víctimas para comunidades indígenas y negras en Colombia. Revista Colombiana de Antropología, 53(2), 85-113. Recuperado de http://www.scielo.org.co/scielo.php?script=sci_arttext\&pi$\mathrm{d}=$ So 486-65252017000200085\&lng=es\&tlng=e

Smith, Neil (2002). Geografía, diferencia y las políticas de escala. Terra Livre, 19, 127-146. Recuperado de http://www.agb.org.br/publicacoes/index.php/terralivre/article/view/162/o

Valderrama-Rentería, Carlos (2018). El arte literario y la construcción oral del territorio. Pensamiento crítico afrocolombiano. Revista Colombiana de Antropología, 54(2), 93-117. https:// doi.org/10.22380/2539472X.463

Valenzuela, Cristina (2004). Reflexiones sobre la dialéctica de escalas en el examen de los procesos de desarrollo geográfico desigual. Biblio $3 w, I X\left(55^{2}\right)$. Recuperado de http://www. ub.edu/geocrit/b3w-552.htm

Valenzuela, Cristina (2006). Contribuciones al análisis del concepto de escala como instrumento clave en el contexto multiparadigmático de la geografía contemporánea. Investigaciones Geográficas, 59, 123-134. Recuperado de http://www.scielo.org.mx/scielo.php?script=sci_arttext\&pid=So188-46112006ooo1000o9\&lng=es\&tlng=es

Velandia, Pedro; Restrepo, Eduardo (2017). Estudios afrocolombianos: balance de un campo heterogéneo. Tabula Rasa, 27, 161-197. https://dx.doi.org/10.25058/20112742.448

Wade, Peter (1997). Gente negra, nación mestiza. Dinámicas de las identidades raciales en Colombia. Bogotá: Siglo del Hombre.

Wade, Peter (1999). Trabajando con la cultura: grupos de rap e identidad negra en Cali. En De montes, ríos y ciudades: territorios e identidades de la gente negra en Colombia (pp. 263-286), editado por Juana Camacho; Eduardo Restrepo. Bogotá: Fundación Natura/Ecofondo/ ICAN. 
Wade, Peter (2004). Los guardianes del poder: biodiversidad y multiculturalidad en Colombia. En Conflicto e (in)visibilidad: retos en los estudios de la gente negra en Colombia (pp. 247-268), editado por Eduardo Restrepo; Axel Rojas. Popayán: Universidad del Cauca.

Zapata, Catalina (2015). El profesor Súper O y la pedagogía del castellano. Muchos colombianos, pocos bien hablados. Bogotá: Envión Editores/Centro de Estudios Afrodescendientes.

Zuluaga, Francisco (1993). Guerrilla y sociedad en el Patía. Cali: Facultad de Humanidades, Universidad del Valle. 